\title{
TURİZME ELEKTRONIKK PAZARLAMA
}

\author{
Nuray Selma ÖZDİÇİNER*, nselma@pamukkale.edu.tr
}

\section{Özet}

Bilgi teknolojilerinde yaşanan inanılmaz hız, işletmeleri değişime zorlamaktadır. Teknolojinin, rekabetin ve tüketicilerin baskısı ile işletmeler, süreçlerini yeniden yapılandırmışlardır. Bu esnada İnternet, önemli bir pazarlama aracı olarak ortaya çıkmıştır. Hem tüketiciler hem de işletmelere yönelik avantajları ile herkes tarafından kabul görerek hızla yayılmaya başlamıştır. İnternet, turizm ürünlerinin dağıtımı ve pazarlaması konusunda önemli değişiklikler yaratmıştır. $\mathrm{Bu}$ çalışmanın amacı, İnternet'in pazarlama aracı olarak turizm sektöründeki kullanımı ve yarattığı değişimi ortaya koymaktır.

Anahtar kelimeler: Turizm, pazarlama, bilgi teknolojileri, İnternet

\section{Electronic marketing in tourism sector}

\begin{abstract}
The incredible speed of information technology experiences, are forced establishments to change. Establishments with the pressure of technology, competition and consumers have reconstructed their process. In the meantime, the internet has emerged as an important marketing tool. With the advantages for both consumers and businesses, it recognized by everyone has begun to spread quickly. Internet has created major changes on distribution and marketing of tourism services. The aim of this study is revealed the change and usage of the internet in the tourism sector as a marketing tool.
\end{abstract}

Keywords: Tourism, marketing, information technology, Internet

JEL Codes: M31, M15

\footnotetext{
* Pamukkale Üniversitesi, Denizli Meslek Yüksekokulu, Turizm ve Otel İşletmeciliği Programı.
} 
Özdipçiner N.S.

\section{BILGİ İLETIŞIM TEKNOLOJILERININ GELIŞSIMI}

İnternet ilk olarak 1960'larda A.B.D. 'de savunma bakanlığ amaçlı olarak kurulmuş ve ARPANET (Advanced Research Projects Auohority Net) adı verilen bu proje, ülke savunması alanında birimler arasındaki bağlantılar, bilgisayarlar aracılığıyla koordineli bir biçimde sağlamak amacını taşımıştır (Breitenbach \& Van Doren, 1999: 558-575). Bilgi teknolojileri son dönemde tüm alanları kapsayarak, yaşamımızın bir parçası haline gelmiştir (Allison, 2002: 80). Teknolojik gelişmeler, insanlık tarihi boyunca bilginin elde edilişi, saklanışı, işlenişi ve iletilişi şeklinde dört farklı aşamada gerçekleşmiştir; İlk aşamadan son aşamaya kadar hız, mesafe, miktar ve elde edilen bilginin güvenilirliğine dair kısıtlar aşama aşama azaltılmıştır (Vural, 2009). Bilgi iletişim teknolojilerinin gelişimi alıcı ve satıcıların bilgi ve veri ağırlıklı bir kanal üzerinden doğrudan iletişimine olanak vermiştir. Bilgi iletişim teknolojilerinin gelişimi (bilgisayarlar, iletişim ağları, etkileşimli televizyon sitemleri), tüketici isteklerindeki artış (esneklik, uyum, kişiye özel mal ve hizmet vb.) rekabet artışı (küresel pazarlar, kısalan ürün yaşam dönemleri, artan risk, hızlı değişimler) ekonomik yapıya etki etmekte ve işletmeleri stratejilerini, ürünlerini ve süreçlerini yeniden belirlemeye itmektedir (http://www.bilgiyonetimi.org/ $\mathrm{cm} /$ pages/mkl_ gos.php?nt=576). Bilgi ve iletişim teknolojilerinde yaşanan bu gelişmeler, herhangi bir coğrafik kısıt olmadan bilgiye ulaşabilme imkanı vermekle beraber, sayısal biçime dönüştürülmüş yazılı metnin, ses ve video görüntülerinin çok hızlı bir şekilde işlenmesini, iletilmesini ve depolanmasını olanaklı kılmıştır (Yılmaz \& Ecevit, 2000; Elibol \& Kesici, 2004). İşte bu önemli iki gelişme, ekonomik kalkınmanın ve toplumsal refahın sağlanmasında elektronik ticarete stratejik bir önem kazandırmaktadır (www.dso.org.tr/eticaret.html). Bilgi teknolojilerinde yaşanan gelişmeler sayesinde rekabet ortamı artmış, iş yapma şekilleri değişmiş, küreselleşme ile pazar koşulları değişmiştir (Gökaliler \& Sabuncuoğlu, 2008: 1317). Televizyon ve telefon aracilığıyla yapilan katalog satışı ile başlayan elektronik ticaret, teknolojik gelişmelerin ürünü olan İnternet'in gelişimi ile hız kazanmıştır. İnternet'in sunduğu sınırsız pazar, şüphesiz elektronik ticaretin bu denli hızlı ve yaygın olarak gelişmesinin ardında yatan nedendir (Küçükgörkey, 2002: 3). 1800-1945 yılları arasında geliştirilen teknolojiler, 20. yüzyılda bilgi üretimi ve elektronik sisteminin de gelişimiyle hız kazanmıştır. Telefon, radyo gibi haberleşme araçlarının kullanılması ve ilk bilgisayarın geliştirilmesi 1930'lara rastlamaktadır. İnsanlar, diğer insanlarla iletişim içine girebileceği yeni bir sosyal çevre oluşturmuş ve bilginin daha serbest dolaşımını sağlayarak 'bilginin demokratikleşmesini sağlamıştır. Elektronik ticarete zemin hazırlayan teknolojik gelişmelerden bir diğeri ise, Elektronik Veri Değişimi (EDI)'dir. Son 50 yıl içinde bilgisayar teknolojisi üç büyük sıçrama yapmıştır. Her bir sıçrama yeni firmaların doğuşuna, hızlı 
değişim dönemlerine girilmesine ve daha sonra az sayıda teknolojinin piyasaya hakim olmasına yol açmıştır. 1950'de IBM ile birlikte "veri işleme", 1960'ların ortasında küçük bilgisayarlar, 1981'de IBM kişisel bilgisayarlar ile bugünün en güçlü şirketleri olan Intel, Dell, HP, Microsoft, Compaq ortaya çıkmıştır (Aksoy, 2003). Elektronik ticaretin gelişim sürecinin, doğal olarak, İnternet'in gelişimine paralel olduğu gözlenmektedir (İnce, 1999: 4). Elektronik ticaretin ayrılmaz unsuru kuşkusuz İnternet'tir (Aksoy, 2003).

\section{INTERNET}

Kelime anlamı "ağlar arası ağ" olarak ifade edilen İnternet, dünya üzerindeki binlerce bilgisayarı birbirine bağlayan, dev bir bilgisayar ağı olarak tanımlanabilir. İnternet'te birbirine bağlanan milyonlarca bilgisayar sayesinde, dünyanın her tarafındaki milyonlarca kişi sınırsızca, kolay bir şekilde ve düşük bir maliyetle iletişim kurabilmektedir (Vural \& Öz, 2007: 222-223). Başlangıçta, sadece birkaç kurumu birbirine bağlamak amacıyla tasarlanan İnternet, artık milyonlarca kişinin bağlandığı dünya çapında devasa bir yapıya kavuşmuştur. Kullanan kişi ve kuruluşların sayısı her geçen gün artmaktadır (Çakır, 2004: 169). Dünyadaki İnternet kullanıcı sayısı 2000 ile 2009 yılları arasında \% 682,8'lik bir artış ile 6.767.805.208 kişiye ulaşmış durumdadır. Türkiye'de ise Haziran 2008 itibariyle İnternet kullanıcı sayısı nüfusunun \% 36,9'unu oluşturan 26,5 milyon kişidir (http://www.internetworldstats.com/stats8.htm) Türkiye, resmi olarak Nisan 1993'te küresel İnternet ağının bir parçası olmuştur. Avrupa ve Kuzey Amerika kadar olmasa da Türkiye'de de İnternet kullanımı hızla yaygınlaşmaktadır (Özturan \& Roney, 2004: 259). İletişim teknolojilerinin ve İnternet kullanımının hızla gelişmesi ile dünyada yeni bir ekonomik düzenin yaygınlaştığı görülmektedir. Buna bağlı olarak; coğrafi sınırlar ortadan kalkmış, satıcı ile alıcının buluştuğu yer olan pazarlar farklı bir boyut kazanmış ve satıcılar tüm dünyayı müşteri kabul ederek, ticari faaliyetlerini web tabanlı sistemlere kaydırmışlardır (Civan \& Bal, 2002: 1011). Elektronik ticarette kurumlar (işletmeler), tüketiciler, vatandaşlar ve devletten oluşan dört taraf bulunmaktadır. Tarafların her birinin elektronik ortamda birbirleriyle olan ilişkileri elektronik ticaretin dört türünü oluşturmaktadır (Dolanbay, 2000: 36). İnternet yoluyla ticaret faaliyetleri; işletmeden işletmeye(B2B), işletmeden tüketiciye(B2C), tüketiciden devlete, E-Government (C2G), işletmeden devlete (B2G) olmak üzere dört şekilde gerçekleştirilmektedir. Bunlar arasında en yaygın olanları ise ilk ikisidir İşlem hacmi açısından işlemlerin önemli bir kısmı işletmeden müşteriye doğru gerçekleşmesine rağmen, işlem değeri olarak işletmeden işletmeye \%80 gibi önemli bir paya sahiptir (Deniz, 2002: 2; Ölçer \& Özyılmaz, 2007: 67; Sarısakal \& Aydın, 2003: 2-3; Barışık \& Yirmibeşcik, 2006: 44). Türkiye'deki e-ticaret uygulamaları ise genellikle isletmeden son kullanıcılara satış biçimiyle gerçekleşmektedir. Türkiye'deki B2C satışlarının, satın alınan 
Özdipçiner N.S.

malların cinsine göre dağılımına bakıldığında, satın alma alışkanlıklarında farklılıklar olduğu görülmektedir. Amerika gibi e-ticaretin gelişmiş olduğu ülkelerde tüketiciler, İnternet yoluyla lüks tüketim mallarından, otomobile ve finansal ürünlere kadar değişen ürünler satın almaktadırlar. Ülkemizde, B2C iş modeli ile çoğunlukla tüketim mallarının satın alınıyor olduğu gözlemlenmektedir (Barışık \& Yirmibeşcik, 2006: 46). İnternet üzerinden yapılan ticarete ilişkin en yaygın endişe, güvenliktir. Daha doğrusu İnternet'te güvenilir finansal işlemlerin yapılıp, yapılamayacağıdır (Tan vd., 2004: 3; Soh vd., 1997: 217-228). Bir diğeri ise mevcut dağıtım kanalına zarar verebileceğidir. Bu endişenin başında, aracı kuruluşların sundukları hizmetler karşılığında aldıkları komisyon ücretlerinde bir azalmanın olabileceği düşüncesi gelmektedir İnternet'te yaşanan problemlerden bir tanesi de tüketicilerin aldatılma endişeleri taşımalarıdır. Özel bilgilerinin gizli tutulmayabileceği endişesidir. Ödemenin, ürün teslimatından önce yapılması ve garanti hizmetleri gibi konularda da tüketiciler endişelenmektedir (Akk1lıç, 2004: 4; Soh vd., 1997: 217-228). Buna rağmen hem tüketiciler hem de işletmeler bu pazarlama aracından vazgeçmemektedirler. İşletmeler ve web tasarımcıları daha güvenli bağlantı yollarını araştırmaktadırlar. İnternet'ten parlama faaliyetlerinin yürütülmesinde web siteleri, elektronik postalar, arama motorları, online reklamlar gibi birçok araç iletişim sürecinde kullanılabilir (Özdemir, 2007: 892). İnternet'in ve özellikle web'in büyük bir gelişim kaydetmesi ve isletmelere çeşitli avantajlar sunması, pek çok isletme ve müşteriyi pazara çekmekte ve böylece pazarlama faaliyetlerini İnternet aracılığı ile gerçekleştirmelerini sağlamaktadır (Ellsworth \& Ellsworth, 1995: 51). İnternet üzerinden uluslararası pazarlama faaliyetleri patlamış ve beraberinde gelen küresel bilgi ağı (Hamill, 1997: 300-323) ortaya çıkmıştır. İşletmelerin, bir kısmı sadece tutundurma amaçlı olarak İnternet'te yer alırken, bir kısmı ise ürün satışı da dahil olmak üzere bir çok pazarlama faaliyetlerinin yer aldığı daha geniş kapsamlı çalışmaktadır (Mathur vd., 1998: 336). İnternet birebir iletişim olanağı yarattığı için doğrudan pazarlama araçlarından biri olarak kullanılmaktadır. Televizyon ve dergi reklamlarından farklı olarak müşterinin bir telefon konuşması yapmasına ya da bizzat isletmeye gitmesine gerek bulunmamaktadır. Böylece üründen haberdar olmak ve satın almak arasındaki süre kısalmaktadır (Pender \& Sharpley, 2005: 248). İnternet'in pazarlama için en önemli yararlarından biri de, siteye giren insanların elektronik bir iz bırakmasıdır. Böylelikle site ziyaretçileri hakkında, nereden, hangi saat diliminde bağlandıkları, sitede ne kadar süre kaldıkları, hangi sayfalara baktıkları ve neler satın aldıkları gibi birçok bilgi elde edilebilmektedir (WTOBC, 1999: 125). Web sitesi sayesinde siteye girenler hakkında ilgili siteye üyelik aracılığı ile de bilgi toplanabilmektedir (Özdemir, 2007: 892). Ancak donanım, yazılım ve personele yapılacak gerekli yatırımlar yüzünden web sitelerinin kısa dönemde kar yapması zor (Middleton \& Clark, 2001: 450) olduğundan küçük 
işletmeler için problem olmaktadır. E-posta, bloglar, podcast ve forumlar etkili birer İnternet pazarlama stratejisi olduklarını kanıtlamışlardır. Bloglar ve forumlar kuruluşların müşterileri ile etkileşimine yardımcı olabilir. E-posta pazarlama, etkin bir araç olarak geniş bir tüketici kitlesine pazarlama hizmeti vermektedir. Web sitelerinde düzenlenen yarışmalar, web pazarlamanın en etkili yollarından biridir. Yeni ürün ve hizmetler hakkındaki online basın bültenleri ve makaleler işletmelerin kendilerini hedef müşterilere tanitmalarına imkan sağlar (http://www.buzzle.com/articles/internet-marketing-strategy.html).

E- Posta Pazarlaması (E- Mail Marketing), pazarlama faaliyetlerinin daha etkin verimli, hızlı ve kapsamlı bir şekilde gerçekleştirilmesi amacıyla, işletmelerin İnternet ortamından yararlanarak iletişim, tanıtımı satış ve pazarlama faaliyetlerinde e-posta yöntemini kullanmalarını ifade etmektedir (Deniz, 2002: 3).

Pek çok işletme ürünlerini tanıtmak, satış fırsatlarını haber vermek gibi nedenlerle e postadan yararlanmaktadır. İşletmeler e-posta aracılığı ile müşterilerine faaliyetleri ile ilgili her türlü bilgiyi, haberi, yeniliği, öneriyi hızla iletip geri bildirim alabilmektedirler. Bu açıdan e posta, doğrudan pazarlamanın geleceği olarak nitelendirilmektedir. Bu uygulama müşterinin izni ile yapılıyorsa yüksek geri dönüş oranları sağlarken, izinsiz gönderilen e postalar, çoğunlukla müşterinin tepkisine neden olmakta ve çoğunlukla okunmadan silinerek, beklediği yarardan çok zarar vermektedir (Deniz, 2002: 3).

İnternet ile iletişim konusundaki son gelişme mobil iletişimdir. Mobil iletişim için önemli olan WAP uygulamalarıdır. Bu teknoloji ile kullanıcılara cep telefonu gibi mobil cihazlar üzerinden her hangi bir ilave cihaza gerek duyulmadan, bir yere bağımlı olmadan İnternet ortamına erişim imkanı sağlanmaktadır.

M-ticaret, e-ticaretin biraz daha genişlemiş bir durumudur. Çünkü m-ticaretin, kullanılan mobil teknoloji sayesinde araçların sabitlik kısıtlarını ortadan kaldırarak, mal ve hizmet alışveriş alışkanlıklarını kökten değiştireceği düşünülmektedir (Sarısakal \& Aydın, 2003: 3).

\section{TURİZM SEKTÖRÜNDE İNTERNET YOLUYLA PAZARLAMA}

Bilgi teknolojisinde 1980'lerden itibaren yaşanan gelişim ile birlikte turizm endüstrinin yapısı kadar işletmecilik uygulamaları ve stratejileri de değişmeye başlamıştır (Ho \& Lee, 2007: 1434; Buhalis \& Law, 2008: 609). Dünyada elektronik ticaretin en yaygın olduğu sektörler arasında; bilişim ve elektronik, telekomünikasyon, finans, perakendecilik, enerji ve turizm yer almaktadır (Ölçer \& Özyılmaz, 2007: 3 ; http://eticaret.garanti.com.tr). Teknolojik yeniliklerle birlikte ortaya çıkan en önemli olgulardan biri de İnternet'tir. İnternet IUYD'2010/1 


\section{Özdipçiner N.S.}

uygulamalarının popülaritesi nedeniyle oteller, havayolları, seyahat acenteleri gibi birçok turizm organizasyonu İnternet'i pazarlama ve iletişim stratejilerinin bir parçası olarak kabul etmiştir (Buhalis \& Law, 2008: 611). Böylece İnternet, turizm pazarında önemli bir araç olmaya başlamıştır (O'Connor \& Murphy, 2004: 473-484; Oh vd., 2004: 425-447). Oteller tarafından (Baloğlu \& Pekcan, 2006: 171176; Fam vd., 2004: 195-207; Scharl, vd., 2004: 257-271), havayolları tarafından (Chu, 2001: 95-100), seyahat acentaları tarafından (Özturan \& Roney, 2000: 259266), kongre ve ziyaretçi büroları tarafından (Yuan vd., 2003: 240-255) ve diğer destinasyonların pazarlama organizasyonları tarafından (Doolin vd.,2002: 557561; Stamboulis \& Skayannis, 2003: 35-43; Stepchenkovaa \& Morrison, 2006: 943956) aktif bir şekilde kullanılmaktadır. Yeni teknolojiler, işletme personelini arka ofisle görevlerinden müşteri hizmetlerine yönlendirerek, turizm pazarını daha etkin hale getirmiştir (Murphy \& Tan, 2003: 543).

Dünya turizm örgütü İnternet'in başarı anahtarının, tüketici ihtiyaçlarının hızlı bir şekilde tanımlanması, doğrudan iletişim, kapsamlı bir sunum, kişiselleştirme ve bilgilerin güncellenmesi olduğunu açıklamıştır (Castaneda vd., 2009: 549). Teknolojik gelişme ile müşteriler kendilerine yönelik çok çeşitli ürün ve hizmetlerden haberdar olmuş ve aralarından bir seçim yapma olanağına kavuşmuşlardır. Bütün sektörlerde olduğu gibi hizmet sektöründe de aynı durum geçerlidir. Gelişmiş ve kolayca ulaşılabilen veri tabanları sayesinde arzu edilen seçim kararı verilebilmektedir (Aksu, 2000: 7). İnternet ve World Wide Web (www)'in 1990'l1 yıllardaki gelişimi bununla birlikte bilginin ve kaynakların global anlamdaki paylaşımı, geleneksel pazarlamayı etkisiz hale getirmiştir (Özturan \& Roney, 2004: 259). İnternet, turizm ürünlerinin dağıtımı ve pazarlanması konusunda büyük bir değişim yaratmış ve bilgi tüketim modelleri yeniden şekillenmiştir (Choi vd., 2007: 118-129). İnternet konaklama, seyahat, yiyecek-içecek ve eğlence sektörlerinde de yoğun olarak pazarlama açısından yorumlanarak değerlendirilmektedir. Ayrıca destinasyonlar açısından da çok büyük fırsatlar sunmaktadır (WTOBC, 1999: 73). Turizm işletmeleri İnternet'i, tanıtım, satış, dağıtım ve müşteri ilişkileri gibi çeşitli pazarlama faaliyetlerinde kullanabilmektedirler. Bunun ötesinde birçok turizm işletmesi etkileşime girdiği diğer turizm işletmeleriyle olan ilişkilerinde de İnternet'i kullanma olanağına sahiptir (Sarı ve Kozak, 2003: 257). Pazarlama ve tanitım aktivitelerindeki en hizlı ve çarpıcı gelişmeler, teknoloji kullanımında yaşanmıştır. Örneğin, geçtiğimiz yıllarda Club Med'in Kuzey Amerika'daki satışları sahip olduğu web dolayısıyla \%40 sıçrama göstermiştir. İnternet kullanıcılarının e posta ile gönderilen linki tıkladıktan sonra tatil satın alma oranları her zamankinden 2,5 kat daha fazla gerçekleşmiştir (http://proquest.umi.com/pqdweb). İspanya, SEDETTUR adıyla Teknolojik Turizm Gelişimi Kuruluşu oluşturmuştur. Bu kuruluş bir yandan bilgi teknolojileri diğer yandan enerji tasarrufu, tasarım, güvenlik, sağlık ve kalite konularında çalışmaktadır. Liechtenstein, İnternet kameraları ile canlı 
yayın yapmaya başlamıştır. Club France, sadece İnternet üzerinden üye kabulü yapmaktadır. İngiltere, dağıtım kanallarında İnternet lehine büyük çaplı bir dönüşümü rapor etmiştir. Bu ülkede, bir zamanların en önemli pazarlama araçları olarak görülen cadde üzeri satış noktaları ve çağrı merkezleri, bu unvanlarını İnternet'e ve doğrudan pazarlamaya bırakmaya başlamıştır. İsviçre, 'Inno Tur' programına devam ederken bir yandan da 2006-2010 yıllarını kapsayan çarpıcı bir Müşteri Yönetim Sistemi' (CRM) projesini faaliyete geçirmiştir (Kaşlı vd., 2009: 10). Tüm bu sistemlerin daha da ileri boyutu sanal gerçeklik olarak karşımıza çıkmaktadır. Sanal gerçeklik, katılımcılarına gerçekmiş hissi veren, bilgisayarlar tarafından yaratılan dinamik bir ortamla karşılıklı iletişim olanağı tanıyan, bir benzetim modelidir. Elektronik ticaret siteleri, sanal gerçeklik tekniklerini bir pazarlama aracı olarak kullanabilmektedir. Televizyon kanalları ve İnternet aracılı̆̆ıla yayınlanan bu tür elektronik pazarlar müşterilerine 24 saat hizmet verebilmektedir. Son zamanlarda sanal gerçeklik teknolojisini kullanan web portalları da yaygınlaşmaya başlamıştır (Bayraktar \& Kaleli, 2007: 2).Yaşanan tüm gelişmeler, getirdiği kolaylıklar, yarattığı ticaret hacmine rağmen çeşitli nedenlerle elektronik ticaretten kaçınılabilmektedir. Turizm sektörü taraflarının e-ticaretten kaçınmasının nedenleri; müşteriden ya da hizmeti sunan isletmeden/ İnternet'ten kaynaklanan nedenler olarak iki farklı grupta incelenebilir. Müşteri açısından kredi kartı ile İnternet ortamında satın almanın yarattığı güvensizlik, bilgisayar kullanımında acemilik, kullanıcının yeterli bilgiye sahip olmaması, ortamda ürün ve hizmetin somut özelliklerinin en aza inmesi gibi nedenlerin yanı sıra yeterli alternatif sayısının bulunmaması, verilerin güncellenmemesi, bilgilerin çok az veya çok fazla olması gibi işletmeden/İnternet'ten kaynaklanan nedenler de bulunmaktadır. Bu konuda Internet Grup ve Net Effect tarafından yapılan bir araştırmanın sonuçlarına göre "İnternet üzerinden alışverişe çıkan müşterilerin ancak $1 / 3^{\prime}$ ü alışverişi tamamlamaktadır, geri kalan müşterilerin \%67'si alışveriş işlemlerini durdurarak ürün ya da hizmeti satın almaktan vazgeçmektedirler (Pirnar, 2005: 43).

Tablo 1'de görüldüğü üzere turizm sektöründeki isletmelerin organizasyon içinde, isletmeler arasında ve müşterileri ile iletişimde bilgi teknolojisini kullanabilecekleri pek çok alan bulunmaktadır. Turizmde kullanılan seyahat hizmetinin üretiminin, reklamının, satın alımının, ödemesinin ve teslimatının ve bunun gibi pek çok faaliyetin İnternet aracılığıyla yapılması mümkündür. İnternet'i turizm sektörü açısından diğer araçlar arasında daha etkin duruma getiren diğer özellikler ise, İnternet'in ses, görüntü ve yazılı bir metni iletebilme işlemlerini aynı anda ve daha hızlı yapabilmesidir. Turizm ürününün en önemli bileşenleri olan konaklama ve seyahatin satışı İnternet üzerinden yıllardır yapılmaktadır. Ancak destinasyon ve yiyecek içecek, diğer hizmetlere kıyasla daha yenidir. 
Özdipçiner N.S.

Tablo 1. Turizm Sektörü İletişim Şekilleri ve Bilgi Teknolojileri Yardımı İle Gerçekleştirilen Faaliyetler

\begin{tabular}{|c|c|}
\hline $\begin{array}{l}\text { Organizasyon İçi İletisim } \\
\text { ve Faaliyetler İntranet }\end{array}$ & $\begin{array}{l}\text { Organizasyonlararası İletişim } \\
\text { ve Faaliyetler Extranet }\end{array}$ \\
\hline $\begin{array}{l}\text { Turizm organizasyonu içerisindeki } \\
\text { bilgi değişimi }\end{array}$ & $\begin{array}{l}\text { Turizm hizmeti üreticileri ve } \\
\text { aracıları arasındaki bilgi değişimi }\end{array}$ \\
\hline $\begin{array}{l}\text { Yönetim } \\
\text { - Stratejik planlama } \\
\text { - Rekabet analizi } \\
\text { - Finansal planlama } \\
\text { - Muhasebe } \\
\text { - Pazarlama araştırması } \\
\text { - Pazarlama stratejisi ve uygulama } \\
\text { - Yönetim istatistikleri } \\
\text { - Operasyon kontrolü } \\
\text { - Yönetim faaliyetleri }\end{array}$ & $\begin{array}{l}\text { Seyahat Öncesi } \\
\text { - Genel bilgi } \\
\text { - Yer ve zaman uygunluğu / Fiyat } \\
\text { araştırmaları } \\
\text { - Pazarlık } \\
\text { - Rezervasyon ve konfirmasyon } \\
\text { - Seyahat ile ilgili belgeler } \\
\text { - Grup listeleri, } \\
\text { - Biletler } \\
\text { - Ödendi / alındı belgeleri }\end{array}$ \\
\hline $\begin{array}{l}\text { Bölümler arası iletişim } \\
\text { - İsletme faaliyetleri } \\
\text { - Bilgi değişimi } \\
\text { - İnsan kaynakları yönetimi } \\
\text { - Personel koordinasyonu }\end{array}$ & $\begin{array}{l}\text { Seyahat Sırasında } \\
\text { - Programın devamı ve takip planı } \\
\text { - Beklenilmeyen olaylar karsısında planların } \\
\text { değişmesi, } \\
\text { - Takip geliştirmesi }\end{array}$ \\
\hline $\begin{array}{l}\text { Şubeler Arası İletişim ve } \\
\text { Fonksiyonlar } \\
\text { - Faaliyetlerin koordinasyonu } \\
\text { - Raporlama ve bütçeleme } \\
\text { - Uygunluk/fiyatlar/bilgi }\end{array}$ & $\begin{array}{l}\text { Seyahat Sonrası } \\
\text { - Ödeme ve komisyonlar } \\
\text { - Geri bildirim ve öneriler } \\
\text { - Şikâyetlerin değerlendirilmesi } \\
\text { - Veri yönetimi ile sadakat kazandırma }\end{array}$ \\
\hline $\begin{array}{l}\text { Turizm Sektörü ile Müşsteri } \\
\text { İletişimi İnternet }\end{array}$ & $\begin{array}{l}\text { Turizm İssletmelerinin Turizm Dışı } \\
\text { İsletmeler ile İletişimi İnternet }\end{array}$ \\
\hline $\begin{array}{l}\text { - Elektronik ticaret } \\
\text { - Seyahat danışmanlığı } \\
\text { - Uygunluk/fiyat/bilgi talepleri } \\
\text { - Rezervasyon ve konfirmasyon } \\
\text { - Rezervasyona ilişkin özel talepler } \\
\text { - Depozitler } \\
\text { - Özel istekler } \\
\text { - Geri bildirim ve şikayetler }\end{array}$ & $\begin{array}{l}\text { Diğer hizmet sunucuları ve destek hizmetleri } \\
\text { - Seyahat formaliteleri ve vizeler } \\
\text { - Aşılar } \\
\text { - Sigorta isletmeleri } \\
\text { - Hava durumu tahmini } \\
\text { - Eğlence ve iletişim } \\
\text { - Bankacılık / finansal hizmetler } \\
\text { - Kredi kartları kullanımı } \\
\text { - İşletmeye ilişkin diğer hizmetler }\end{array}$ \\
\hline
\end{tabular}

Kaynak: Buhalis Dimitros (2003), E-Tourism, Prentice-Hall., Aktaran: Prrnar, İge (2005) Turizm Endüstrisinde E-Ticaret, Ekonomik ve Sosyal Araştırmalar Dergisi, 1, 11-12. 


\subsection{Konaklama Sektöründe İnternet}

Teknoloji, konaklama işletmeleri için rekabette ve örgütsel performansı arttırmada önemli bir stratejik boyut haline gelmiştir (Wang \& Qualls, 2007: 560). Oteller, uluslar arası pazarlama ve reklam açısından en aktif İnternet kullanıcilarıdır (Soh vd., 1997: 217-228). Birçok otel isletmesi bu avantajdan yararlanmak için kendi web sitelerini oluşturmuştur (Pırnar, 2005: 45). Web siteleri, çekici grafik ve resimlerle birlikte olanaklar, hizmetler ve fiyatlara ilişkin bilgiler sunarlar (Soh vd., 1997: 217-228). İşletmelerin başarıyı yakalayabilmeleri için sadece İnternet'te var olmaları yeterli olmayıp (Liang \& Law, 2003: 193-208), web sitelerinin, ziyaretçileri çekmeleri ve tüketici konumuna dönüştürmeleri gerekmektedir (Auger, 2005:119-137). Çünkü web siteleri karar aşamasında tüketici davranışları üzerinde önemli rol oynamaktadır (Odgers, 2001: 45). Bu nedenle sitenin zengin ve çekici içeriği ile tüketicilerin hem alışveriş yapmaları hem de siteyi tekrar ziyaret etmeleri sağlanmalıdır (Haas, 2002: 637). Aksi takdirde potansiyel tüketiciler, kolaylıkla başka bir işletmenin web sitesine kayabilmektedirler (Taylor \& England, 2006: 83). Türkiye'deki otel işletmelerinin web tasarımına yönelik bir araştırmaya göre; otel işletmeleri web sitelerinde bulunan başlıca ortak özellikler olarak oda ve otel resimleri, siteye kolay ulaşım imkânı, iletişim ve ulaşım bilgisi, çoklu dil seçeneği, ana sayfaya kolay ulaşım, kullanışlı menü, sistemin hızlı açılması, hızlı indirilme ve e-posta ile rezervasyon olduğu belirlenmiştir (Bayram \& Yayl, 2009: 23). Tüketicilerin, otellerin web sitelerini kullanma nedenleri arasında zamanlarının değerli olması ve fiyat (Chung \& Law, 2003: 119-125; Liang \& Law, 2003: 193-208) başlica iki temel unsurdur. Tüketiciler İnternet'i kullanarak, turistik ürünler hakkında daha fazla bilgiye kısa sürede ulaşabilmekte ve karşılaştırma yapabilmektedirler ( $\mathrm{O}^{\prime}$ Connor \& Murphy, 2004: 474). Otellerin İnternet sitelerini kullanım amaçları farklılık gösterebilmektedir. İnternet, pazarlama ve satış aracı olarak daha sık kullanılmasının yanı sıra, rezervasyon aracı olarak da kullanılmaktadır (Pırnar, 2005: 45). Çok sayıda tüketici geleneksel dağıtım kanallarını atlayarak otellere doğrudan rezervasyon yapmaktadır (Jeong vd., 2003: 161). Oteller de en iyi fiyat garantisi ile doğrudan rezervasyon yapanları cezp etmeye çalışmaktadırlar (O'Connor \& Murphy, 2004: 474). Çevrimiçi alışveriş yapanların \% 90'ın rezervasyona karar vermelerinde \% $6^{\prime}$ lik bir indirimin etkili olduğunu belirlenmiştir. $\mathrm{Bu}$ indirim oranı, otel işletmelerinin seyahat acentelerine verdikleri komisyondan (genel olarak \%8) daha azdır (Wong \& Law, 2005: 311329). Bu gelişmelere rağmen, geleneksel yöntemlerin tanıtımda en etkin yol olduğunu düşünen otellerde bulunmaktadır. İnternet aracılığıyla alınan rezervasyonların oranları, telefon ve faks ile alınan rezervasyonlara oranla daha düşüktür. Fakat İnternet kullanıcılarının artması ve nesil değişimi, zaman yetersizliği ve artan enformasyon yoğunluğu gibi sosyal değişimler, tüketicilerin 
Özdipçiner N.S.

genel anlamda elektronik ticareti kabullenmelerine yardımcı olacaktır (Pırnar, 2005: 45).

\subsection{Seyahat Sektöründe İnternet}

Dağıtım kanallarının amacı, doğru ürünün, doğru miktarda, doğru yerde ve tam zamanında bulunmasını sağlamaktır (Wayne \& Berthon, 2000: 425). İnternet, bu amacın gerçekleştirilmesini kolaylaştırmaktadır. İnsanlar kendi yaptıkları organizasyonlara daha çok güven duymakta ve daha çok keyif almaktadırlar. Ayrıca İnternet üzerinde aradığı her türlü bilgiye kısa sürede ulaşan turist, gerekli rezervasyonları da online yapmayı turizm deneyiminin bir parçası olarak hem eğlenceli hem de kullanışlı ve rahat bulmaktadır (WTOBC, 1999: 73). Gün geçtikçe bağımsız seyahate yönelik artan ilgi ve insanların kendi yaptıkları araştırmalar ve seyahat düzenlemeleri doğrultusunda hareket etme eğilimleri sonucunda, paket turlara, tur operatörlerine ve seyahat acentalarına daha az ihtiyaç duyulmaktadır (WTOBC, 1999: 73). Seyahat ve turizm siteleri dünya çapında önemli oranda gelişme gösterdiği halde, turizm pazarlaması için geleneksel kitle medyası ve seyahat acentaları gibi aracılar kullanılmaya devam edilmektedir (Lau vd., 2001: 55-56). Seyahat sektörü hala, İnternet aracılı̆̆1 ile en fazla satın alınan ilk üç hizmet kategorisi içindedir (Heung, 2003: 370-378). Çünkü seyahat kuruluşları, tüketiciler açısından bir marka görevi üstlenmektedirler. Tüketiciler çeşitli hizmetlere İnternet üzerinden ulaşabilseler de, aracı seyahat kuruluşlarına olan ihtiyaç her zaman var olacaktır (Akkılıç, 2004: 5).

Seyahat ve turizm endüstrisi, parçalı, bilgi odaklı bir endüstridir. Bu durum, seyahat endüstrisi için İnternet'ten sağlanacak yararı oldukça önemli bir hale getirmektedir (Andreu vd., 2009: 2). Bu nedenle İnternet'i kullanan seyahat kuruluşlarının sayısı gün geçtikçe artmaktadır (Akkılıç, 2004: 5). İnternet üzerinden gerçekleştirilecek işlemler ise doğrudan rezervasyondan, son tüketiciye kolay ödeme koşulları sunulmasına ve seyahat acentaları ile tur operatörleri ve diğer turizm ürün ve hizmet sunucuları arasında değişik alanlarda gerçekleşebilmektedir (Pırnar, 2005: 9). Seyahat acentalarında kullanılan bilgisayarlı rezervasyon sistemleri ise İnternet'in diğer bir kulanım alanıdır. Bilgisayarlı rezervasyon sistemleri, bilgi depolamak ve almak için oluşturulmuş bilgisayar sistemleridir. 1970'li yıllardan beri bu sistemler seyahat acentaları tarafından dağıtım kanalı olarak kullanılmaktadır (Tsai vd., 2005: 786). Havayolları için tasarlanan ve işletilen CRS'ler sonra seyahat acentelerinin rezervasyon, bilet satış gibi işlemleri için genişletilmiş, birçok havayolunu içeren global dağıtım sistemleri (GDS) tarafından kullanılmaya başlanmıştır. GDS şirketleri, İnternet ağ geçitleri üzerinden tüketiciye erişilebilir hale gelmiştir. Modern GDS'ler genel olarak 
havayollarında biletleme yapmanın yanı sira otel rezervasyonu ile araba kiralama imkanını da sağlar. Ayrıca ana sisteme doğrudan bağlı olmamasına rağmen bazı pazarlarda demiryolu rezervasyonlarına da imkan vermektedir. Amedeus (\%49,2), Sabre (\%44,7), Worldspan by Travelport (\% 26,5), Galileo by Travelport $(\% 19,7)$ önemli pazar payları ile bu pazarın liderleridir. Bilgisayarlı rezervasyon sistemleri, turizm isletmelerinin ve turistik destinasyonların küresel ölçekte yayılışını kolaylaştırmaktadır. Bu sistemler, turistik hizmet sağlayıcılarına ürünlerini küresel ölçekte tanıtım, satış ve kontrol olanağı sunarken, doluluk oranlarını yükseltme ve mevsimsellik sorunlarını azaltma konularında yardımcı olmaktadır. Ayrıca, ekonomik ömürlerini uzatırken, karlılık oranlarını arttırmalarına imkan sağlar. Bilgisayarlı rezervasyon sistemleri müşterilerin, destinasyonlar, seyahat paketleri, konaklama ve eğlence hizmetleri, fiyatlar ve bu hizmetlerin erişilebilirliği hakkında bilgilere kolayca erişme ve karşılaştırma yapmalarına olanak vermektedir. Ayrıca, detaylı bilgilere daha kolay erişim ve uygun fiyatlı kişiselleştirilmiş hizmetler sunulabilmek için de altyapı sağlar (Pirnar, 2005: 46).

Seyahat teknolojisindeki son gelişme, sanal tur teknolojileri içeren sanal turizmdir. Sanal Gerçeklik (Virtual Reality) programları, tüketicilere ve turistlere oturdukları yerde seçtikleri tatil merkezinde dolaşıp neler yapabileceklerini, neleri yiyip içebileceklerini ve neleri satın alabileceklerini gösterebilmektedir. Üç boyutlu, görsel, işitsel ve dokunmatik teknolojisi ile üretilen bu programlar son derece etkindir (Pırnar, 2005: 47). Bu gün dünya üzerinde pek çok destinasyon, otel ve müze bu teknoloji ile gezilebilmekte, turistler gitmek ve görmek istedikleri yerleri sanal ortamda dolaşabilmektedirler. Gerçek bir turizm deneyiminin yerini tutması mümkün değilse de bu durumun gelecekte turizmin yerine geçebileceği bile düşünülmektedir.

\subsection{Yiyecek İçecek İşletmelerinde İnternet}

Her ne kadar teknoloji turizmin tüm alanlarında etkili olsa da İnternet'in yiyecek içecek sektörüne etkileri üzerinde pek fazla çalışma bulunmamaktadır. Alan yazında İnternet'in yiyecek içecek sektöründe kullanımına ilişkin çalışmalar daha çok, marka (Weber vd., 2006: 1463-1466) çocuklar ve ergenler (Alvy \& Calvert, 2008: 710-713; Henry \& Story, 2009: 353-359) ve web siteleri (White, 1996: 39-59; White, 1998: 413-418)üzerinedir. Bir kısmı da yiyecek güvenliğini içermektedir.

İnternet'in yiyecek içecek firmaları için doğrudan pazarlama aracı olarak kullanımı önem arz etmektedir (Arguelles, 1998: 13). Yiyecek endüstrisinde Pizza Hut zinciri, Silicon Vadisindeki kullanıcılara İnternet üzerinden sipariş verebileceklerini duyurduktan sonra dünya çapında tanınmıştır. Amerika'daki Coca-Cola, Burger King, Pepsi, KFC, ve McDonald's gibi hızlı servis yapan restoranlar mobil pazarlamanın kısa mesaj, elektronik kupon, video gibi çeşitli 
Özdipçiner N.S.

araçları ile ürünlerinin tanıtımını yapmaktadırlar. Böylece artan bir oranda mobil kullanıcı pazarlama alanının içine çekilmektedir (Montgomery \& Chester, 2009: 520).

Zincir işletmelerin başı çektiği İnternet kullanımı, en küçük işletmelere kadar yaygınlaşmış bulunmaktadır. Bu gün, İstanbul'da İnternet üzerinden simit siparişi alan simitçiler bile bulunmaktadır. Teknolojinin kullanımı post modern pazarlama uygulamaları ile bu sektöre büyük yenilikler getirmiştir. Bilgisayar ekranından oluşan bir masada yemek yiyebilmek, siparişini verdiğiniz yemeğin tabak içindeki görüntüsünü masanızda bulmak ve siparişinizi beklerken yine masa şeklindeki bu ekrandan mutfağı izleyebilmek artık bir hayal değildir.

\subsection{Destinasyonların İnternet Üzerinden Pazarlaması}

Birçok turist merak ettiği ve ilgi duyduğu destinasyonla ilgili daha fazla bilgi edinme arayışı içindedir (Lee vd., 2006: 815-828). Destinasyon pazarlaması için elektronik ticaret ve İnternet kullanımı son derece faydalıdır ve destinasyonlarını bilhassa kongre ve benzeri nedenler ile iş seyahati grubuna elektronik araçlar ile tanıtan ve pazarlayan destinasyon yöneticileri e-ticarette kazançlı olmuşlardır (Pırnar, 2005: 48). İnternet'in bilgi kaynağ destinasyon yönetim örgütleri, daha çok kişiye daha uygun koşullarda ulaşabilmek ve turizm pazarında rekabetçi olabilmek için web sitelerini kurmuşlardır. Web sitesinin başarısı ise, teknolojideki gelişmeler ve trend değişimleri doğrultusunda sitenin gözden geçirilmesi ve yeniden düzenlenmesinin yanı sıra site aracılığıyla doğru ve tam bilgi sunulmasına bağlıdır (Lee vd., 2006: 815-828; Law vd., 2004: 100-107). Bir iletişim aracı ve dağıtım kanalı olarak İnternet, turistlerin destinasyon hizmetleri hakkında kolayca bilgi sahibi olmalarını ve bu hizmetleri kendilerinin organize ederek seyahatlerini istekleri ve bütçeleri doğrultusunda planlamalarını sağlamaktadır. İnternet, turistlerin karar verme süreçlerine yardımcı olabilmek için kapsamlı, zamanlı ve gerekli bilgiyi sanal çevreden rahatlıkla elde edebilmelerini sağlamaktadır. (Law vd., 2004: 100-107). Destinasyon yönetim örgütleri İnternet aracılığı ile yalnızca olası turistlerle değil, seyahat acentaları ve tur operatörleri ya da otel, restoran gibi turizm isletmeleri ile de aynı kolaylık ve hızla iletişim kurabilmektedir. Destinasyon web siteleri, turizm işletmeleri için de bir bilgi kaynağ 1 işlevini görmektedir (Özdemir, 2007). Potansiyel gücü bu kadar yüksek olan bir aracın en etkin şekilde kullanılması ve yönetilmesi gerekmektedir. Web sitesinde sunulan bilginin içeriği ve sunum sekli, potansiyel bir turisti ikna edebilmek için çok önemlidir (Law vd., 2004: 100-107).

\section{SONUÇ}

Baş döndürücü bir hızla gelişen teknoloji, tüm sektörleri olduğu gibi turizm sektörü üzerinde de yapısal değişimlere neden olmuştur. Havayolu şirketleri, 
seyahat acentaları ve tur operatörleri oteller, yoğun rekabette ayakta kalabilmek için bu yeni pazarlama seklini kullanmak zorundadırlar. Türkiye'nin turizm pazarının Avrupa ağırlıklı olduğu ve onların da teknolojik gelişmeleri yakından takip ettiği düşünülecek olursa, İnternet üzerinden yapılan pazarlama faaliyetlerinin Pazar payımızı koruyabilmek için bile mutlaka takip edilmesi gereken bir strateji olduğu açıtır. Turizm dağıtım kanalındaki işletmeler, Internet'in sağladığı doğrudan pazarlama nedeniyle her ne kadar aracılık faaliyetlerinin azalacağını düşünseler bile, bu değişim onların da kendilerini geliştirmelerine ve teknolojiye uyum sağlayarak, bu değişimden daha güçlü çıkabilmelerine olanak vermektedir. Aslında turizm yapısı itibari ile esnek olmasına rağmen hızlı hareket etmeyi gerektiren bir endüstridir. İnternet'in turizm pazarlamasında kullanımı hem işletmelere hem de potansiyel turistlere hız ve esneklik sağlamaktadır. Teknolojiyi hayatımızın içine alıp almama gibi bir lüksümüz olmadığına göre onu bir pazarlama aracı olarak nasıl daha etkin kullanabileceğimiz üzerine odaklanmak gerekir.

\section{KAYNAKÇA}

Aksoy, A. (2003). Ticaret'te Yeni Bir Boyut: Internet, www.habur.net/yazilar/silopihaber/ aksoy.htm, Erişim: 12.11.2003.

Akkılıç, M. E. (2004). Uluslararası Bir Pazarlama Aracı Olarak İnternet'in (A). Grubu Seyahat Acenteleri Açısından Önemi ve Kullanım Durumu, Fırat Üniversitesi Sosyal Bilimler Dergisi, 14(1), 146-156.

Aksu, A.A. (2000). Otel İşletmelerinin Başarısını Etkileyen Dış Çevre Faktörleri, Balıkesir Üniversitesi Sosyal Bilimler Enstitüsü Dergisi, 3(4), 269-281.

Allison, J. E. (2002). Technology, Development And Democracy, International Conflict anf Information Age, State University of NY Pres.

Altınok, S., Sugözü, İ.H. \& Çetinkaya, M. (2003). Geleneksel Ticaretten Yeni Ekonomiye Elektronik Ticaretin Temel Ekonomik Etkileri, http://inet-tr.org.tr/ inetconf9/bildiri/ 89.pdf

Alvy, L. M. \& CALVERT, S. L. (2008). Food Marketing on Popular Children's Web Sites: A Content Analysis, Journal of the American Dietetic Association, 108(4), 710-713.

Andreu A, L, ALDAS, J. A, BIGNE, J. E. \& MATTILA. S. E. (2009). An Analysis Of E-Business Adoption And Its Impact On Relational Quality In Travel Agency-Supplier Relationships, Tourism Management, 1-11.

Arguelles, G., Collins, R., Dadakas, D., Perkins, B. A., Taylor, H. \& Jensen, K., (1998). Preliminary Analysis of Internet Use for Direct Marketing by the 
Özdipçiner N.S.

Tennessee Food and Beverages Industry, Agricultural Marketing $\mathcal{E}$ Agribusiness Studies, 1-16.

Auger, P. (2005). The Impact of Interactivity and Design Sophistication on The Performance of Commercial Websites for Small Businesses, Journal of Small Business Management, 43 (2)., 119 - 137.

Baloğlu, S. \& Pekcan, Y. A. (2006). The Web Design And Internet Site Marketing Practices Of Upscale And Luxury Hotels In Turkey, Tourism Management, 27(1). 171-176.

Barışık, S. \& Yirmibeşcik, O. (2006). Türkiye'de Yeni Ekonominin Oluşum Sürecini Hızlandırmaya Yönelik Uyum Çabaları, ZKÜ Sosyal Bilimler Dergisi, 2(4), 39-62.

Bayraktar, E \& Kaleli, F. (2007). Sanal Gerçeklik ve Uygulama Alanları, Akademik Bilişim Konferansı, 31 Ocak - 2 Şubat, Dumlupınar Üniversitesi, Kütahya, 1-6.

Bayram, B. \& Yaylı, A. (2009). Otel Web Sitelerinin İçerik Analizi Yöntemiyle Değerlendirilmesi, Elektronik Sosyal Bilimler Dergisi, 8(27), 347-379.

Breitenbach, C. S. \& Van DOREN, D. C. (1999). Value Added Marketing In The Digital Domain; Enhancing The Utility Of The Internet, Journal of Consumer Marketing, 15(6), 558-575.

Buhalıs, D \& Law, R. (2008). Progress In Information Technology And Tourism Management: 20 Years On And 10 Years After The Internet-The State Of E Tourism Research, Tourism Management, 29, 609-623.

Castaneda, J. A. Frias, D. M. \& Rodriguez, M. A. (2009). Antecedents Of Internet Acceptance And Use As An İnformation Source By Tourists, Online Information Review, 33(3), 548-567.

Choı, S., Lehto, X. Y. \& Morrıson, A. M. (2007). Destination Image Representation on the Web: Content Analysis of Macau Travel Related Websites, Tourism Management, 28(1), 118-129.

Chu, R. (2001). What Online Hong Kong Travelers Look for on Airline / Travel Websites?, Hospitality Management, 20, 95 - 100.

Chung, T. \& Law, R. (2003). Developing A Performance Indicator For Hotel Websites, International Journal of Hospitality Management, 22(1), 119-125.

Civan, M. \& Bal, V. (2002). E-Ticaret ve KOBI'lerin Geleceği, I. Ulusal Bilgi, Ekonomi ve Yönetim Kongresi, 10-11 Mayıs, Hereke- Kocaeli.

Çakır, V. (2004). Yeni İletişim Teknolojilerinin Reklam Üzerine Etkileri, Selçuk İletişim, 3(2), 168-181. 
Deniz, B. (2002). Yeni Bir Pazarlama Yöntemi Olarak Elektronik Posta Pazarlamas1, Journal of Kültür University, 2002/2, 1-10.

Dolanbay, C. (2000). E-ticaret, Sistem Yayınları, Ankara.

Doolin, B., Burgess, L. \& Cooper, J. (2002). Evaluating The Use Of The Web For Tourism Marketing: A Case Study From New Zealand, Tourism Management, 23, 557-561.

Elibol, H. \& Kesici, B. (2004). Çağdaş İşletmecilik Açısından Elektronik Ticaret, Selçuk Üniversitesi Sosyal Bilimler Enstitüsü dergisi, 11-303, ISSN, 1302-1796.

Ellsworth, J.H. \& Ellsworth, M. V. (1995). Marketing On The Internet, John Wiley \& Sons.

Fam, K. S., Foscht, T. \& Collıns, R. D. (2004). Trust And The Online RelationshipAn Exploratory Study From New Zealand, Tourism Management, 25, 195-207.

Gökaliler, E. \& Sabuncuoğlu, A. (2004). Bilgi İletişim Teknolojileri İle Reklam Ajanslarının Değişen Yüzü: İnteraktif Ajanslar, Journal of Yasar University, 3(10), 1313-1330.

Haas, R. (2002). The Austrian Country Market: A European Case Study on Marketing Regional Products And Services in a Cyber Mall, Journal of Business Research, 55 (8), 637 - 464.

Hamill, J., (1997). Internet and International Marketing, International Marketing Review, 14(5). 300-323.

Henry, A. E. \& Story, M. (2009). Food and Beverage Brands That Market to Children and Adolescents on the Internet: A Content Analysis of Branded Web Sites, Journal of Nutrition Education and Behavior, 41(5), 353-359.

Heung, V. C. S. (2003). Barriers To Implementing E-Commerce In The Travel Industry: A Practical Perspective, International Journal of Hospitality Management, 22(1), 111-118.

Ho, C. I., \& Lee, Y. L. (2007). The Development of An E-Travel Service Quality Scale, Tourism Management, 28, 1434-1449.

İnce, M.(1999). Elektronik Ticaret: Gelişme Yolundaki Ülkeler İçin İmkanlar ve Politikalar, DPT Raporu.

Jeong, M., Oh. H. \& Gregorre, M. (2003). Conceptualizing Web Site Quality And its Consequences in The Lodging Industry, Hospitality Management, 22, 161 175.

Kaşlı, M., İlban, M. O. \& Şahin, B. (2009). Modern Pazarlama Stratejileri: AB ve Türk Turizmi, Elektronik Sosyal Bilimler Dergisi, 8(27), 79-98. 
Özdipçiner N.S.

Küçükgörkey, A. (2002). Yeni Ekonomi ve Elektronik Ticaret, I. Ulusal Bilgi, Ekonomi ve Yönetim Kongresi, Hereke- Kocaeli, 2-11.

LAU, K.N., LEE, K., Lam, P.Y. \& Ho, Y. (2001). Web-site Marketing for the Travel-and-Tourism Industry, Cornell Hotel and Restaurant Administration Quarterly, 42, 55-62.

Law, R., Leung, K. \& Wong, J. (2004). The Impact of The Internet on Travel Agencies, International Journal of Contemporary Hospitality Management, 16(2) 100-107.

Lee, G., Ca1, L. \& O'leary A. J. (2006). WWW. Branding States. US: An Analysis of Brand-building Elements in the US State Tourism Websites, Tourism Management, 27(5), 815-828.

Liang, K. \& Law, R. (2003). A Modified Functionality Performance Evaluation Model for Evaluating The Performance of China Based Hotel Websites, Journal of Academy of Business and Economics, 2 (2), 193 - 208.

Mathur, L. K., Mathur, I. \& Gleason, K. (1998). Services Advertising and Providing Services on the Internet, The Journal of Services Marketing, 12(5), 334347.

Middleton, V.T.C. \& Clarke, J. (2001). Marketing in Travel and Tourism, Butterworth - Heinemann, Oxford.

Montgomery, K. \& Chester, J. M. S. W. (2009). Interactive Food and Beverage Marketing: Targeting Adolescents in the Digital Age, Journal of Adolescent Health, 45, 18-29.

Murphy, J \& Tan, I. (2003). Journey To Nowhere? E-Mail Customer Service By Travel Agents In Singapore, Tourism Management, 24, 543-550.

O'connor, P. \& Murphy, J. (2004). Research on Information Technology in The Hospitality Industry, Hospitality Management, 23, 473 - 484.

Odgers, D.G. (2001). Turizm Endüstrisinde Bilgi Sistemi Uygulamalarn ve Bilgi Sistemlerinin Turizm Alanların Pazarlamasında Uygulaması, Yüksek Lisans Tezi, Gazi Üniversitesi, Sosyal Bilimler Enstitüsü.

Oh, H., Kım, B.-Y. \& Shın, J.H. (2004). Hospitality and tourism marketing: Recent developments in research and future directions, Hospitality Management, 23, 425-447.

Ölçer, F. \& Özyılmaz, A. (2007). Elektronik Ticaret ve Sanal Organizasyonlarda Uygulanması, Süleyman Demirel Ün. İ̈BF Dergisi, 12(2), 67-94. 
Özdemir, G. (2007). Destinasyon Pazarlamasında İnternetin Rolü, Journal of Yasar University ,2(8), 889-898.

Özturan, M. \& Roney, S. A. (2004). Internet Use Among Travel Agencies In Turkey: Exploratory Study, Tourism Management, 25, 259-266.

Pender, L. \& Sharpley, R. (2005). The Management of Tourism, Sage Publications, London.

Pırnar, İ. (2005). Turizm Endüstrisinde E-Ticaret, Ekonomik ve Sosyal Araştırmalar Dergisi, Güz, 1, 28-55.

Sarı, Y. \& Kozak, M., (2005). Turizm Pazarlamasına İnternetin Etkisi: Destinasyon Web Siteleri İçin Bir Model Önerisi, Akdeniz İ.I..B.F. Dergisi, 9, 248-271.

Sarısakal, M. N. \& Aydın, M. A. (2003). E-Ticaretin Yeni Yüzü Mobil Ticaret, Havacilık Ve Uzay Teknolojileri Dergisi, 1(2), 83-90.

Scharl, A., Wöber, K. W. \& Bauer, C. (2004). An Integrated Approach To Measure Web Site Effectiveness In The European Hotel Industry, Information Technology \& Tourism, 6, 257-271.

Soh, C. Mah, Q. Y., Gan, F. J., CHEW, D, \& REID, E. (1997). The Use Of The Internet For Business: The Experience Of Early Adopters In Singapore, Internet Research, 7(3), 217-228.

Stamboulıs, Y. \& Skayannis, P. (2003). Innovation Strategies And Technology For Experience-Based Tourism, Tourism Management, 24, 35-43.

Stepchenkovaa, S. ve Morrison, A. M. (2006). The Destination Image Of Russia: From The Online Induced Perspective, Tourism Management, 27, 943-956.

Tan, A., Baydaş, A. \& Aksen, N. (2004). Kahramanmaraş İlindeki İşletmelerin Pazarlama Faaliyetlerinde İnternet'i Kullanma Eğilimleri, KSÜ. Fen ve Mühendislik Dergisi, 7(2), 83-89.

Taylor, M. J. \& England, D. (2006). Internet Marketing: Web Site Navigation Design Issues, Marketing Intelligence E Planning, 24 (1), 77 - 85.

Tsa1, H. T., Huang, L. \& Lin, C. G. (2005). Emerging E-Commerce Development Model For Taiwanese Travel Agencies, Tourism Management, 26, 787-796.

Vural, A. Z. B. (2005). Enformasyon İletişim Teknolojileri: Gelişimi, Doğası ve Ahlaki Konular, http://155.223.1.158/edergi/yenid/s1/9.pdf, 12. 01.2010.

Vural, İ \& ÖZ, M. (2007). Bir Reklam Aracı Olarak İnternet, Sosyal Bilimler Enstitüsü Dergisi, 23(1)., 221-240.

Wang, Y. \& Qualls, W. (2007). Towards a Theoretical Model of Technology Adoption in Hospitality Organizations, Hospitality Management, 26, 560 - 573. 
Özdipçiner N.S.

Wayne, C \& Berthon, P. (2000). The Impact Of The Internet On Distribution Value Chain: The Case Of South African Tourism Industry, International Marketing Review, 18(4), 420-431.

Weber, K.Story, M. \& Harnack, L. (2006). Internet Food Marketing Strategies Aimed at Children and Adolescents: A Content Analysis of Food and Beverage Brand Web Sites, Journal of the American Dietetic Association, 106(9), 1463-1466.

White, G.K. ( 1996). An On-Line Survey of Food and Beverage Consumers on the Internet: An Evaluation of the Survey Methodology, Marketing Bulletin, 2003, 14, Article 3, Reprinted from Research On-Line, 1, 39- 59 http://marketingbulletin.massey.ac.nz/V14/MB_V14_A3_White.pdf

White, G.K., \& Manning, B. J.(1998). Commercial WWW Site Appeal: How Des It Affect Online Food and Drink Consumers' Purchasing Behavior, British Food Journal, 100(9), 413-418.

Wong, J. \& Law, R. (2005). Analysing The Intention to Purchase on Hotel Websites: A Study of Travellers to Hong Kong, Hospitality Management, 24, $311-329$.

Wtobc (1999). World Tourism Organization Business Council. Chapter 1: Introduction In Marketing Tourism Destinations Online: Strategies for the Information Age, Madrid: World Tourism Organization. Available at: http://www.world-tourism.org/isroot/wto/pdf/1133-1.pdf.

Yılmaz, Ö. D. \& Yılmaz, B. S. (2010). Küreselleşme ve Bilgi Teknolojilerinin

Turizm Endüstrisine Etkileri, http://www.bilgiyonetimi.org/cm/pages/mkl_gos.php?nt=576, Erişim:18.01.2010

Yılmaz, C. \& Ecevit, Z. (2000). Küçük ve Orta Büyüklükteki İşletmelerde İnternet Kullanımı, 5.Ulusal Pazarlama Kongresi, Antalya.

Yuan, Y., Gretzel, U. \& Fesenmaier, D. R. (2003). Internet Technology Use By American Convention And Visitors Bureaus, Journal of Travel Research, 41(3), 240-255.

http://eticaret.garanti.com.tr. Erişim: 1.4.2010.

http://proquest.umi.com/pqdweb, PR Newswire. New York: Feb 17, 2010, http://www.internetworldstats.com/stats8.htm Erişim:22.4.2010

http://www.buzzle.com/articles/internet-marketing-strategy.html, Internet

Marketing Strategy, Erişim:22.4.2010

http://www.dso.org.tr/eticaret.html 